\title{
Sex in pregnancy
}

\author{
Claire Jones MD, Crystal Chan MD, Dan Farine MD
}

$\mathrm{P}$ regnant women and their partners often ask whether or not sex is allowed in pregnancy and what consequences may result from engaging in sexual activity. Can sex be used to induce labour? When is it safe to have sex after delivery? This primer outlines the existing evidence to aid physicians in counselling their patients.

Sexual activity is common in pregnancy, but the frequency varies widely, with a tendency to decrease with advancing gestational age. ${ }^{1,2}$ Decreased sexual activity may be attributable to nausea, fear of miscarriage, fear of harming the fetus, lack of interest, discomfort, physical awkwardness, fear of membrane rupture, fear of infection or fatigue. ${ }^{2}$ Libido and sexual satisfaction may also be negatively affected by a woman's self-perception of decreased attractiveness. Typically, as pregnancy progresses, there is a decrease in the achievement of orgasm and sexual satisfaction, and an increase in painful intercourse. $^{3}$

\section{Potential complications}

Potential complications of sex in pregnancy include preterm labour, pelvic inflammatory disease, antepartum hemorrhage in placenta previa and venous air embolism (Table 1). ${ }^{4-11}$

\section{Preterm labour}

The risk of preterm labour differs among pregnant women, depending on the presence or absence of specific risk factors. These include previous preterm labour, multiple gestation and cervical incompetence.

Restriction of sexual intercourse is routinely recommended for the prevention and management of threatened preterm labour because of the theoretical risk of intercourse as a method of inducing labour (Box 1). However, the existing literature is contradictory and limited by study design, reporting bias and the rarity of preterm labour as an event. ${ }^{5,6}$

\section{Women at low risk}

Mills and coworkers followed 10981 singleton low-risk pregnancies and found no increase in the frequency of preterm labour in women who abstained from sex compared with those having sex. ${ }^{12}$ Chhabra and Verma followed 140 pregnant women at over 28 weeks' gestation and found that women who had sex and symptoms of lower genital tract infection had a higher incidence of preterm labour compared with women with sexual activity but no symptoms. ${ }^{7}$ A multicentre prospective study compared the rate of preterm delivery in women who had frequent intercourse (defined as once per week or more) with those who did not. ${ }^{6}$ Frequent intercourse was associated with an increased risk of preterm delivery only in the subset of women colonized with Mycoplasma hominis or Trichomonas vaginalis. ${ }^{6}$ Women with low-risk pregnancies who have no symptoms or evidence of lower genital tract infection should be reassured that sex does not increase the risk of preterm delivery.

\section{Women at increased risk}

There is limited evidence to guide recommendations on sexual activity in women who are at increased risk of preterm labour because of a history of preterm labour, multiple gestation or cervical incompetence. Yet, these are the women who are usually advised to abstain from sex.

Yost and colleagues studied the impact of sexual intercourse on recurrent preterm delivery in women with a previous spontaneous preterm
Competing interests: None declared.

This article has been peer reviewed.

Correspondence to: Dr. Claire Jones, claire.jones@utoronto.ca

CMAJ 2011. DOI:10.1503 /cmaj.091580

\section{- Ker POINTS}

- Sex is generally considered safe in pregnancy.

- Abstinence should be recommended only for women who are at risk for preterm labour, or antepartum hemorrhage because of placenta previa.

- There is little evidence to show that sex at term may help induce labour, but this practice is considered safe in women with low-risk pregnancies.

- The resumption of intercourse postpartum should be dictated by a woman's level of comfort. 
birth at less than 32 weeks' gestation. ${ }^{5}$ Frequency of sexual intercourse at the time of study enrolment had no effect on the incidence of recurrent preterm delivery. However, women with a higher number of lifetime sexual partners had an increased risk of preterm delivery. Previous authors have postulated that this may be because of an increased incidence of asymptomatic bacterial colonization of the genital tract in women who have had more sexual partners, leading to subclinical infection, which can induce preterm labour. For this reason, the current guidelines from the Society of Obstetricians and Gynaecologists of Canada recommend that women at increased risk for preterm labour receive screening and treatment for bacterial vaginosis. ${ }^{4}$

Women with twin pregnancies are also at greater risk of preterm labour, but a study of 126 women with twin gestations showed no significant difference in the frequency of sexual activity among patients who delivered at term compared with those who delivered preterm. ${ }^{13}$ In addition, patients with a cervical cerclage for cervical incompetence are generally advised to restrict sexual intercourse, although there is no evidence that this improves outcomes.

In populations at increased risk for preterm labour, there is no evidence to suggest a clear benefit from restricted sexual activity; however, this is a simple intervention that causes no harm and may be a reasonable recommendation until better evidence emerges.

\section{Pelvic inflammatory disease}

A common misconception is that pregnancy is protective against sexually transmitted infections and pelvic inflammatory disease. This is not only false, but may also contribute to a delay in treat-

Table 1: Potential complications of sex in pregnancy

\begin{tabular}{|c|c|}
\hline Complication & Evidence in the literature \\
\hline Preterm labour & $\begin{array}{l}\text { - No clear increased risk in patients with low- } \\
\text { risk pregnancies }{ }^{4} \\
\text { - Increased risk with genital tract infection and } \\
\text { bacterial colonization in women with low-risk } \\
\text { pregnancies or with a history of preterm } \\
\text { delivery, }\end{array}$ \\
\hline $\begin{array}{l}\text { Pelvic inflammatory } \\
\text { disease }\end{array}$ & $\begin{array}{l}\text { - One review with } 57 \text { cases in pregnant } \\
\text { adolescents }^{8} \\
\text { - One case of tubo-ovarian abscess }\end{array}$ \\
\hline $\begin{array}{l}\text { Antepartum } \\
\text { hemorrhage }\end{array}$ & $\begin{array}{l}\text { - None published } \\
\text { - Theoretical risk with placenta previa }\end{array}$ \\
\hline Venous air embolism & $\begin{array}{l}\text { - One review with } 19 \text { cases in pregnancy or } \\
\text { puerperium } \\
\text { - One review with } 18 \text { deaths from venous air } \\
\text { embolism in pregnancy }{ }^{11}\end{array}$ \\
\hline
\end{tabular}

ment with substantial maternal and fetal consequences. Theoretically, pregnant women should be at decreased risk for developing pelvic inflammatory disease because of natural barriers to ascending infection created by the mucous plug and the obliteration of the uterine cavity by fusion of the decidua capsularis and parietalis by the 12th week of gestation. However, the upper genital tract is still at risk for ascending infection in the first trimester, and chronic upper genital tract infection can recur during pregnancy. A large chart review showed that pelvic inflammatory disease and pregnancy can coexist in adolescents and should be on the differential diagnosis for pregnant patients presenting with abdominal pain. ${ }^{8}$ Likewise, tubo-ovarian abscess has also been described in pregnancy. ${ }^{9}$

\section{Antepartum hemorrhage in placenta previa}

In the setting of placenta previa, Williams Obstetrics warns that "examination of the cervix ... can cause torrential haemorrhage." ${ }^{14}$ Likewise, it has been theorized that penile contact with the cervix during intercourse can result in a similar risk of hemorrhage, and as a result, patients with placenta previa are advised to abstain from sexual activity during pregnancy. However, there is a paucity of prospective data to support or refute this recommendation.

One study showed the safety of transvaginal ultrasound probes in the setting of placenta previa by measuring the mean angle between the rigid probe and the axis of cervix to be $63.8^{\circ}$ and concluding that "it is not physically possible for the vaginal probe, which is fixed and straight, to enter the cervix without being aligned with the cervical canal." ${ }^{15}$ Although there are no studies on the angle of penile contact with the cervix during intercourse in pregnancy, one may be able to extrapolate from the study of transvaginal probes.

Furthermore, the torrential hemorrhage described with digital examination of the cervix is more likely due to the flexion of the distal phalanges, allowing the fingers to enter the cervix and come into direct contact with the placenta. Despite limited evidence, it is probably safest to advise patients with placenta previa to abstain from sexual activity to reduce the theoretical risk of catastrophic antepartum hemorrhage.

\section{Venous air embolism}

Venous air embolism, a rare but potentially lifethreatening event, has been reported in pregnant and peripartum patients having orogenital and penile-vaginal sex..$^{10,11}$ Although the true incidence of venous air embolism in pregnancy is unknown, Batman and coauthors reported 18 
deaths caused by venous air embolism out of 20 million pregnancies. ${ }^{11} \mathrm{~A}$ recent review of the literature identified 22 instances of venous air embolism associated with sexual activity; 19 of the 22 instances occurred during pregnancy or the puerperium. ${ }^{10}$ Eighteen of the 22 women died.

Two conditions must be present for venous air embolism to take place: direct communication between the source of air and vasculature, and a pressure gradient favouring passage of air into circulation. During pregnancy and the puerperium, there is direct communication from the vagina to the distended uteroplacental vasculature, and air can be forced into the cervical canal by oral insufflation or the piston-like effect of a penis or finger in the vagina. Air introduced into the venous circulation and pulmonary vasculature can result in serious morbidity, in addition to cardiopulmonary arrest and death.

Although this entity is rare, pregnant patients should be advised to avoid orogenital sex with air insufflation because this activity seems to confer an increased risk. ${ }^{10}$ Penile-vaginal sex, especially in the rear-entry position where the level of the uterus is above the level of the heart, may also increase the risk of embolism. ${ }^{10}$

\section{Sex for induction of labour}

At term, nipple and genital stimulation have been advocated as a way of naturally promoting the release of endogenous oxytocin, and prostaglandins released in semen as a method of cervical ripening. There is limited literature available, but overall there is no evidence to support the theory that sex at term has any effect on Bishop score (a cervical assessment used to predict the success of achieving a vaginal delivery), spontaneous onset of labour, cesarean delivery rates or neonatal outcomes. However, there are no known harmful consequences in patients with low-risk pregnancies. Details of the available literature on sex for induction of labour can be found in Appendix 1, available at www.cmaj.ca /cgi/content/full/cmaj.091580/DC1.

\section{Sex in the postpartum period}

Patients often ask when they can resume having sex postpartum and what potential risks exist. In theory, early intercourse could result in disruption of sutures, infection, dehiscence, bleeding and hematoma, or fistula formation. These complications have been found to be more common after third- or fourth-degree lacerations or midline episiotomies, or in patients with endometritis. ${ }^{16}$ However, most of these postpartum complications occur within the first two weeks, and
Box 1: Theoretical mechanisms of induction of labour by sexual activity

- Nipple and genital stimulation may induce oxytocin release from the posterior pituitary, causing uterine contractions.

- Prostaglandins released from mechanical stimulation of the cervix may cause cervical ripening.

- Prostaglandins in semen may cause cervical ripening.

very few women are comfortable enough to have sex until the perineum is healed.

The most common postpartum complication associated with sexual activity is painful intercourse. In a review of the literature on postpartum sexual dysfunction, $90 \%$ of women resumed sex by three to four months postpartum, and sex was usually painful for the first one to two months but improved with time. ${ }^{17} \mathrm{~A}$ few studies have shown a quicker return to intercourse if no perineal trauma was present at delivery. ${ }^{17,18} \mathrm{In}$ addition, increased rates of painful intercourse and sexual dysfunction have been noted with operative vaginal delivery, with inconsistent results for cesarean deliveries. ${ }^{17}$

One common cause of painful intercourse postpartum is vaginal dryness due to the hypoestrogenic state induced by breastfeeding. Rowland and coauthors showed that breastfeeding women were less likely to have resumed intercourse by the time of the first postpartum visit compared with women who were not breastfeeding. ${ }^{19}$

When advising patients about resuming intercourse postpartum, there are no specific guidelines. It seems reasonable to advise them to try intercourse when they are feeling comfortable enough to do so. Generally, women may experience some pain with intercourse, which can be ameliorated by lubrication, or, if needed, vaginal estrogen, and they should be reassured to expect improvement with time.

\section{Conclusion}

Sex in pregnancy is normal. There are very few proven contraindications and risks to intercourse in low-risk pregnancies, and therefore these patients should be reassured. In pregnancies complicated by placenta previa or an increased risk of preterm labour, the evidence to support abstinence is lacking, but it is a reasonable benign recommendation given the theoretical catastrophic consequences. Although intercourse has never been proven as a useful method of induction of labour, patients with low-risk pregnancies should feel comfortable engaging in sex- 
ual activity as they please, which is the same advice that should guide the resumption of intercourse in the postpartum period.

\section{References}

1. Aslan G, Aslan D, Kizilyar A, et al. A prospective analysis of sexual functions during pregnancy. Int J Impot Res 2005; 17:154-7.

2. Orji EO, Ogunlola IO, Fasubaa OB. Sexuality among pregnan women in South West Nigeria. J Obstet Gynaecol 2002;22:166-8

3. Gokyildiz S, Beji NK. The effects of pregnancy on sexual life. J Sex Marital Ther 2005;31:201-15.

4. Yudin MH, Money DM. Screening and management of bacterial vaginosis in pregnancy. J Obstet Gynaecol Can 2008;30:702-8.

5. Yost NP, Owen J, Berghella V, et al. Effect of coitus on recurrent preterm birth. Obstet Gynecol 2006;107:793-7.

6. Read JS, Klebanoff MA. Sexual intercourse during pregnancy and preterm delivery: effects of vaginal microorganisms. The Vaginal Infections and Prematurity Study Group. Am J Obste Gynecol 1993;168:514-9.

7. Chhabra S, Verma P. Sexual activity and onset of preterm labour. Indian J Matern Child Health 1991;2:54-5.

8. Acquavella AP, Rubin A, D'Angelo LJ. The coincident diagnosis of pelvic inflammatory disease and pregnancy: Are they compatible? J Pediatr Adolesc Gynecol 1996;9:129-32.

9. Sherer DM, Schwartz BM, Abulafia O. Management of pelvic abscess during pregnancy: a case and review of the literature. Obstet Gynecol Surv 1999;54:655-62.

10. Truhlar A, Cerny V, Dostal P, et al. Out-of-hospital cardiac arrest from air embolism during sexual intercourse: case report and review of the literature. Resuscitation 2007;73:475-84.

11. Batman PA, Thomlinson J, Moore VC, et al. Death due to air embolism during sexual intercourse in the puerperium. Postgrad
Med J 1998;74:612-3.

12. Mills JL, Harlap S, Harley EE. Should coitus late in pregnancy be discouraged? Lancet 1981;2:136-8.

13. Neilson JP, Mutambira M. Coitus, twin pregnancy, and preterm labour. Am J Obstet Gynecol 1989;160:416-8.

14. Obstetrical hemorrhage. In: Cunningham FG, Leveno KJ, Bloom SL, et al., editors. Williams obstetrics. 22nd ed. New York (NY): McGraw-Hill; 2005. p.821.

15. Timor-Tritsch IE, Yunis RA. Confirming the safety of transvaginal sonography in patients suspected of placenta previa. Obstet Gynecol 1993;81:742-4.

16. Duggal N, Mercado C, Daniels K, et al. Antibiotic prophylaxis for prevention of postpartum perineal wound complications: a randomized controlled trial. Obstet Gynecol 2008;111:1268-73.

17. Hicks TL, Goodall SF, Quattrone EM, et al. Postpartum sexual functioning and method of delivery: summary of the evidence. J Midwifery Womens Health 2004;49:430-6.

18. Radestad I, Olsson A, Nissen E, et al. Tears in the vagina, perineum, sphincter ani, and rectum and first sexual intercourse after childbirth: a nationwide follow-up. Birth 2008;35:98-106.

19. Rowland M, Foxcroft L, Hopman WM, et al. Breastfeeding and sexuality immediately postpartum. Can Fam Physician 2005;51: 1366-73.

Affiliations: From the Department of Obstetrics and Gynecology, University of Toronto, Toronto, Ont.

Contributors: All of the authors conducted the literature review, wrote and edited the paper, and approved the final version submitted for publication.

Acknowledgement: The authors thank Marilyn Sutandar for her contribution to the original search and analysis of the literature.

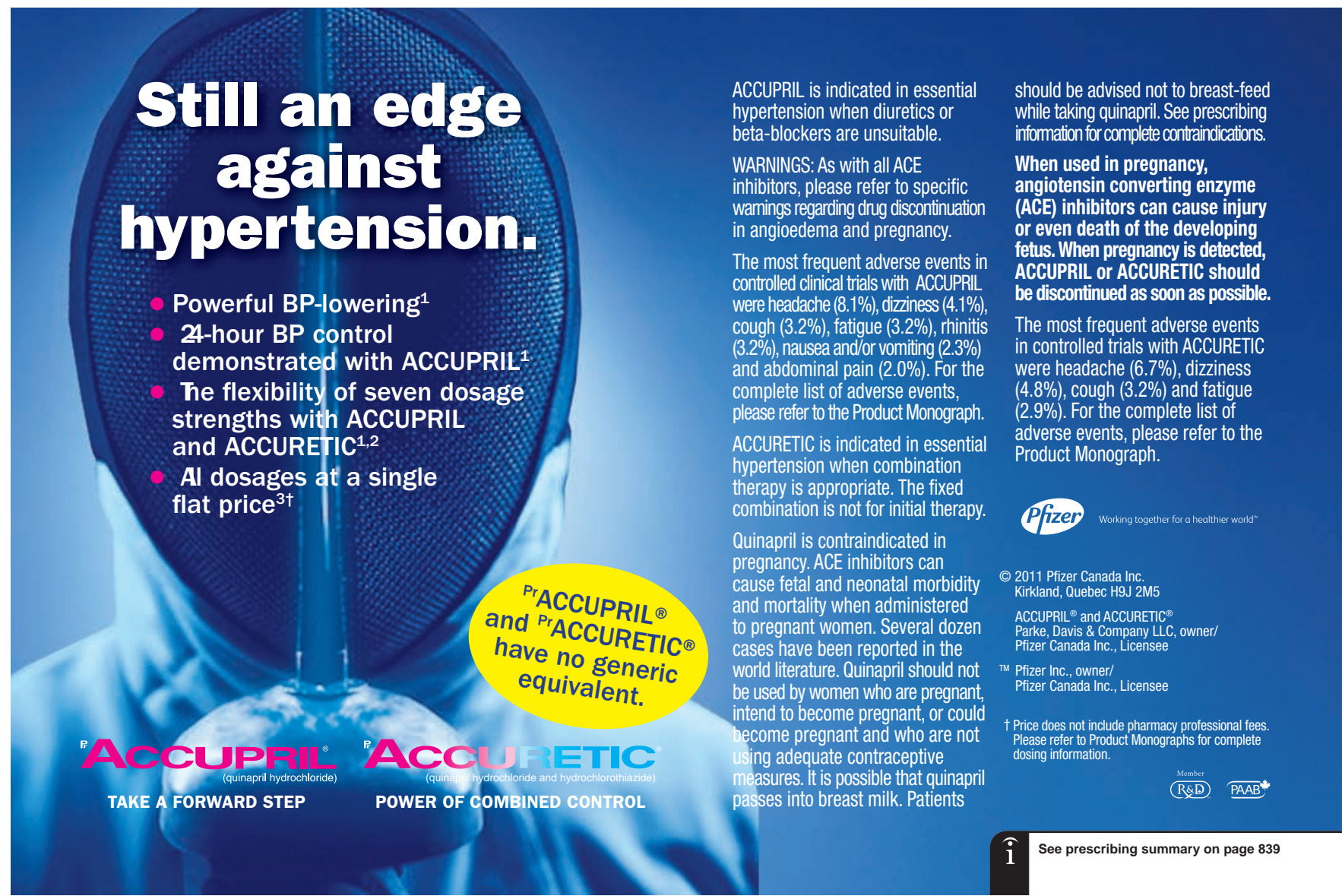

